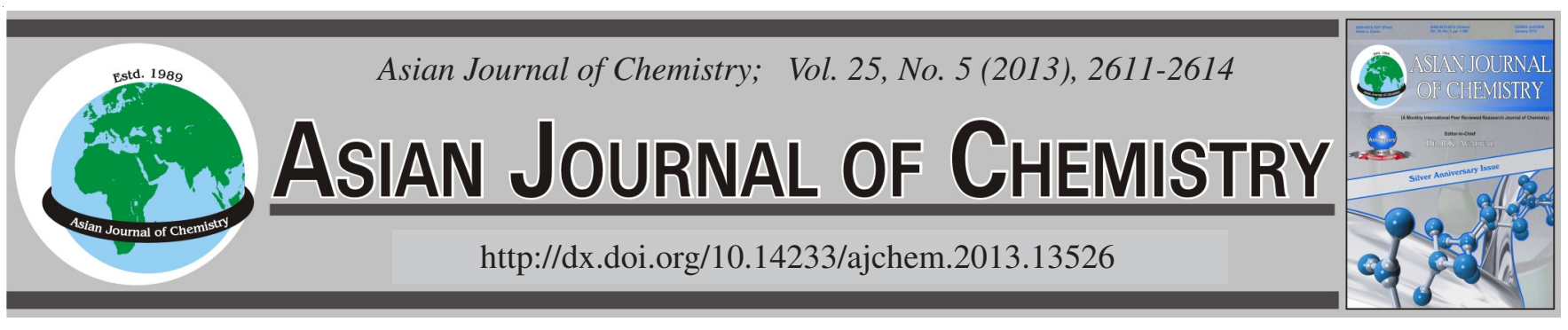

\title{
Electropolishing of Cylindrical Copper Cavities
}

\author{
A.M. AhMED ${ }^{1, *}$ and Mona DAREWISH ${ }^{2}$
}

${ }^{1}$ Department of Chemistry, Faculty of Science, Alexandria University, Ibrahimia, P.O. Box 426, Alexandria 21321, Egypt
${ }^{2}$ Department of Chemistry, Faculty of engineering, Tanta University, Tanta, Egypt

*Corresponding author: E-mail: ahmedeladl@live.com

(Received: 28 January 2012;

Accepted: 15 November 2012)

AJC-12413

\begin{abstract}
The rates of electropolishing of cylindrical copper cavities were studied by measuring the limiting current for anodic dissolution of copper from phosphoric acid using a cylindrical anode placed inside cavity. Variables used were cavity diameter, cavity length, phosphoric acid concentrations and temperatures. It's found that the rate of electropolishing decreases by increasing cavity, phosphoric acid concentrations increases by diameter of cavity, depth and temperatures. Thermodynamic parameters were given. The data can be correlated by the equation $\mathrm{Sh}=1.54(\mathrm{Sc} . \mathrm{Cr}) 0.29(\mathrm{~d} / \mathrm{h})$.
\end{abstract}

Key Words: Electropolishing, Phosphoric acid, Limiting current, Thermodynamic parameters, Cylindrical copper cavities.

ᄂ - - - - - - - - - - - - - - - - - - - - - - - - -

\section{INTRODUCTION}

Chemical, physical and mechanical properties of copper make it the world third most widely used metal after iron and aluminum. It is used in very essential fields such as electronically applications, building construction, industrial machinery, equipment, transportation and consumer products ${ }^{1}$.

Copper surface seems rough and complex under microscopic investigation, due to the presence of macro and micro scales of humps and depression. The enhancement of surface smoothness requires removal of more than one micron of scratches (leveling), while production of both smooth and bright surface requires removal of less than one micron of scratches and then, a highly reflective surface is obtained ${ }^{2}$.

Electropolishing has been employed industrially for a variety purposes, the most common being surface preparation for further treatment or analysis and surface finishing for cosmetic purpose $\mathrm{e}^{3,4}$.

Much work has been done on the phenomenon of electropolishing ${ }^{5,6}$ and most of this work was directed towards the elucidation of the polishing mechanism as well as establishing conditions for polishing of different metals and alloys. Electropolishing is a diffusion controlled process ${ }^{7}$ which takes place at the limiting current and electropolishing can therefore be treated quantitatively using the theory of mass transfer for the cathodic deposition of metal and metal powder ${ }^{8}$. Some work has been done on the study of electropolishing under forced convection mass transfer conditions ${ }^{9-13}$. An investigation involving copper and copper-base alloys in a stirred cell is due to the study of $\mathrm{Gabe}^{14}$ and strongly suggests a diffusionlimiting mechanism at low temperature. Fouad et al. ${ }^{15}$ studied a mass transfer under free convection in the electropolishing of vertical copper electrodes in phosphoric acid.

Although much work has been carried out on the polishing of different geometries, little has been done on the electropolishing of cavities. Cavities are frequently encountered in practice either alone or as a part of a more complex structure. The presence of cavities in a work piece represents a problem to the metal finishing industry owing to the difficulty of obtaining a uniform current distribution inside these cavities during electroplating and electropolishing.

Electropolishing of cylindrical cavities was studied ${ }^{16,17}$ under natural convection using a horizontal cathode placed outside the cavities anode. Under these conditions it was found that electropolishing was only uniform for relatively large diameter cavities. For deeper or smaller diameter cavities the upper part of the cavity was polished while the lower part was only etched. The object of the present work is to overcome this problem by using a central wire cathode place inside the cavity to improve the primary current distribution instead of the horizontal cathode placed outside the cavity ${ }^{16}$. The study was carried out by measuring the limiting current (the polishing current) of vertical cylindrical copper cavities in phosphoric acid.

\section{EXPERIMENTAL}

The apparatus (Fig. 1) consisted of a cell and electrical circuit. The cell was a glass beaker of volume $1 \mathrm{~L}$ containing 


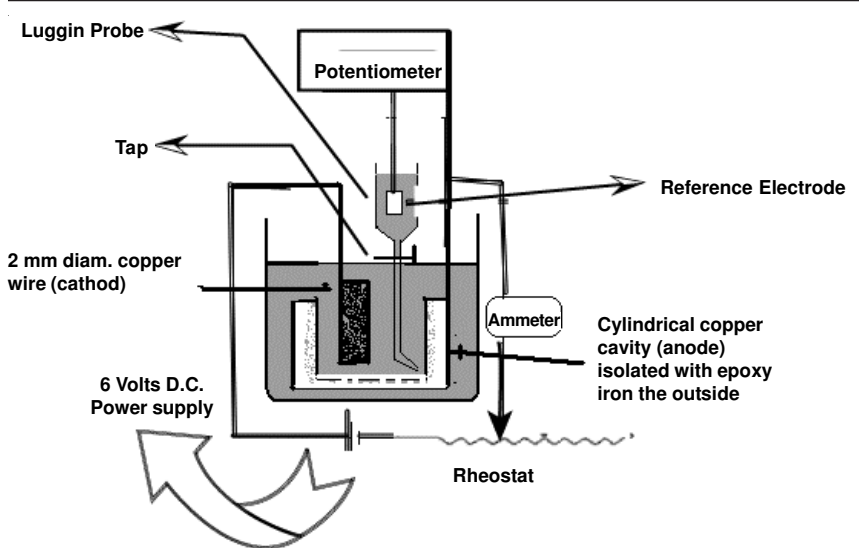

Fig. 1. Cell and electrical circuit

at its bottom a vertical cylindrical cavity anode made of copper.

The cathode was $2 \mathrm{~mm}$ diameter copper wire placed in the center of the cavity with its end distance $c a$. 2-3 mm from the cavity bottom. Anodes were prepared by machining cylindrical cavity with a flat bottom in a copper cylinder. Cavity diameter ranged from 0.5-2.1 $\mathrm{cm}$ while cavity depth ranged from $0.5-4.0 \mathrm{~cm}$ an insulated copper wire $2 \mathrm{~mm}$ in diameter was brazed to each anode to serve as a current feeder. The anode surface was insulated from outside the cavity with epoxy resin. The electrical circuit consisted of a $6 \mathrm{~V}$ DC power supply with a voltage regulator and a multi-range ammeter is connected in series with cell. Polarization curves from which the limiting current was obtained were plotted by increasing the cell current stepwise and measuring the steady state anode potential against a reference electrode. The reference electrode consisted of a copper wire immersed in the cup of a Luggin tube filled with $\mathrm{H}_{3} \mathrm{PO}_{4}$ of concentration similar to that in the cell, the tip of the Luggin tube was placed 0.5-1.0 mm from the cavity wall. The potential difference between the anode and the reference electrode was measured by means of a high impedance voltmeter. Five phosphoric acid concentrations (6, 8, 10, 12 and $14 \mathrm{M}$ ) were prepared from A.R. grade $\mathrm{H}_{3} \mathrm{PO}_{4}$ and distilled water. The relationship of i-E curve of copper in $\mathrm{H}_{3} \mathrm{PO}_{4}$ was determined at different temperatures, 25, 30, 35 and $40{ }^{\circ} \mathrm{C}$ using water ultra-thermostates.

\section{RESULTS AND DISCUSSION}

Electropolishing technique is a highly efficient method for cleaning and brightening of metals and alloys. It has received much attention due to its practical and academic interests, some workers tried to attain bright and smooth surface of copper, aluminum, stainless steel and other alloys by applying electropolishing method ${ }^{18-20}$.

The process is diffusion controlled, depending on the concentration gradient forming a selective electrochemical dissolution and improving polarization efficiency of $\mathrm{Cu}$ surface, where the down and up thickness differences are eliminated $^{21-24}$. It typically occurs at the mass transfer limiting current at highly anodic potentials, where the metal surface is smoothed out.

The limiting current value that determines the polishing efficiency depends on the rate of mass transfer of $\mathrm{Cu}^{2+}$ ions from the diffusion layer to the bulk of the solution. The rate of mass transfer depends on the relative ionic movement, geometry of the anode, temperature, the type and physical properties of the electrolyte.

Fig. 2 shows a set of typical polarization curves obtained using different phosphoric acid concentrations at $25^{\circ} \mathrm{C}$ the limiting current (I) at which polishing takes place was determined from these polarization curves and used to calculate the mass transfer coefficient $(\mathrm{K})$ of copper polishing in $\mathrm{H}_{3} \mathrm{PO}_{4}$ from the equation:

$$
\mathrm{K}=\frac{\mathrm{I}}{\mathrm{zFC}}
$$

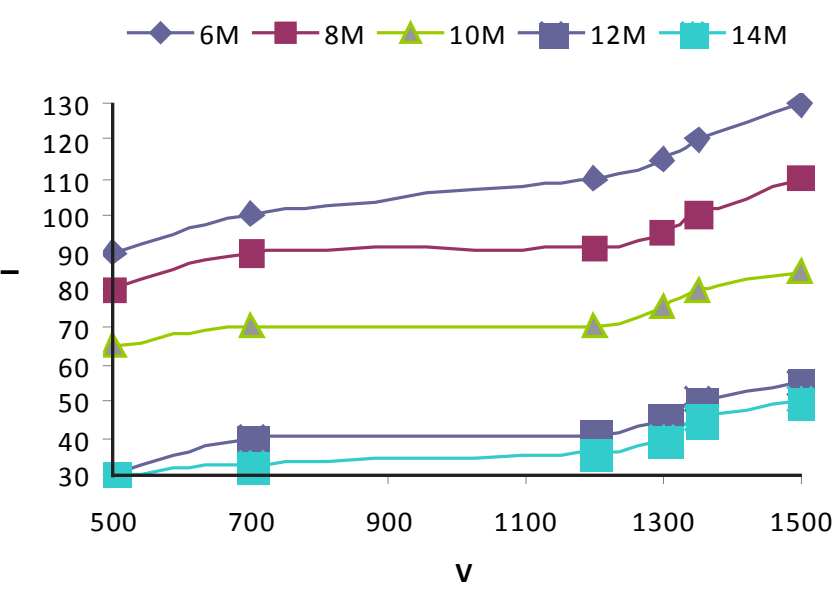

Fig. 2. Relation between limiting current and volt at different phosphoric acid concentrations

The saturation solubility (C) of copper phosphate $\left(\mathrm{as}^{2+}\right)$ in different phosphoric acid concentrations was obtained from the literature ${ }^{25}$. Figs. 3 and 4 show the effect of cavity diameter and cavity depth on the mass transfer coefficient at $25^{\circ} \mathrm{C}$. The mass transfer coefficient decrease slightly with increasing cavity and increases with increasing cavity depth. The increase in the mass transfer coefficient with depth disagrees with the prediction of hydrodynamic boundary layer according to which the mass transfer should decreases with increasing depth by virtue of the increase in the thickness of hydrodynamic boundary layer and diffusion layer ${ }^{26}$. The discrepancy between the present finding and the hydrodynamic boundary layer theory may be explained as follows: A cylindrical cavity is composed of a vertical cylindrical wall and a horizontal circular bottom, the interaction between the flow conditions at the cavity wall and cavity bottom determines the limiting current at which cavity polishing takes place. At the cavity wall a downward laminar flow.

Takes place owing to the density difference between the bulk solution $\left(\mathrm{H}_{3} \mathrm{PO}_{4}\right)$ and the interfacial solution which consists of a saturated solution of copper phosphate in phosphoric $\operatorname{acid}^{26-29}$.

According to Sedahmed and Shemilt ${ }^{16}$, when this downward natural convection stream reaches the bottom of the cavity, turbulence is generated their owing to the change in the flow direction. This turbulence enhances the rate of mass transfer inside the cavity with a consequent increase in the rate of polishing. The increasing in the mass transfer coefficient with 


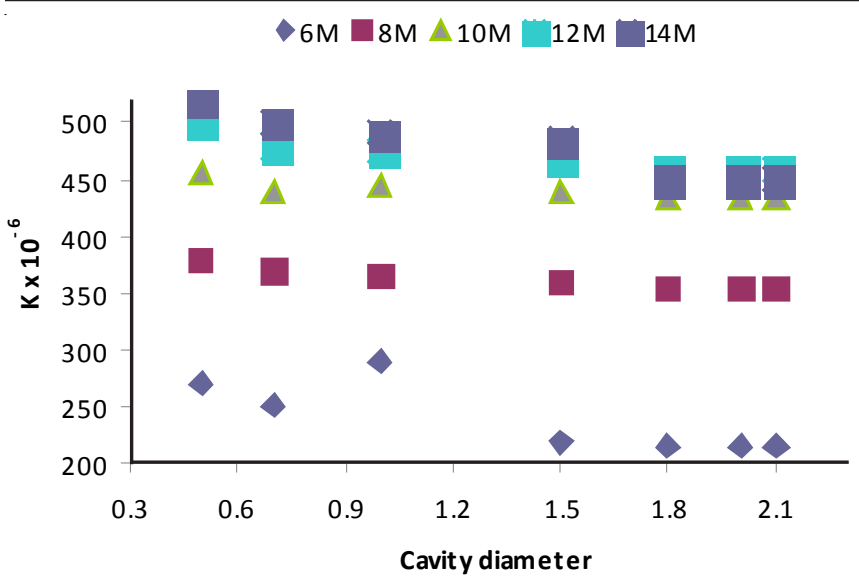

Fig. 3. Effect of cavity diameter on the mass transfer coefficient at $25^{\circ} \mathrm{C}$

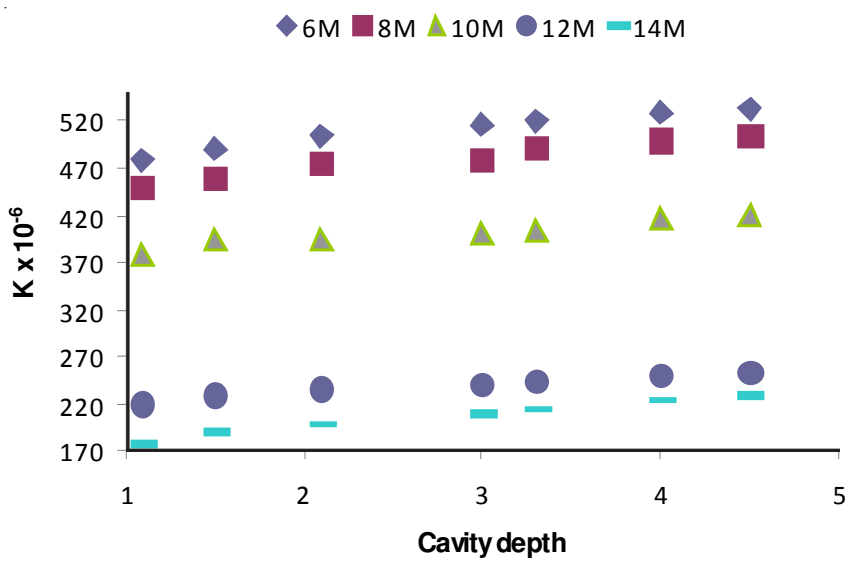

Fig. 4. Effect of cavity depth on mass transfer coefficient

increasing cavity height may be attributed to the fact that the amount of downward flowing fluid which generates turbulence at the cavity bottom increases with increasing cavity depth with a subsequent increase in the turbulence promotion ability of the falling fluid.

To assist the metal finishing engineering in predicting the limiting current required to polish cylindrical cavities, used a central cathode, an overall mass transfer equation was investigated using the dimensionless groups ( $\mathrm{Sh}, \mathrm{Gr}$ and $\mathrm{Sc}$ ) usually used in correlation natural convection mass transfer in electrochemical process. Fig. 5 shows that the data can be correlated by the equation:

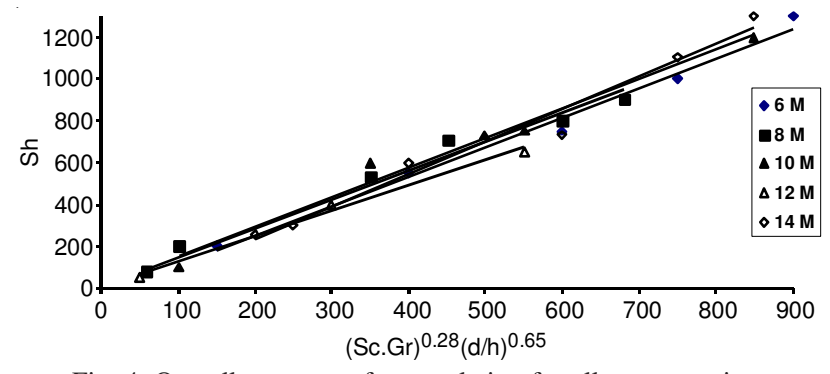

Fig. 4. Overall mass transfer correlation for all concentrations

$$
\mathrm{Sh}=1.54(\mathrm{Sc} . \mathrm{Gr}) 0.29(\mathrm{~d} / \mathrm{h})
$$

With an average deviation of $\pm 3.3 \%$; cavity diameter was used as a characteristic length in calculating Sh and Gr in the following equation. When the cavity depth was used as characteristic length in calculating Sh and Gr the following equation was obtained:

$$
\mathrm{Sh}=0.99(\mathrm{Sc} . \mathrm{Gr})^{0.303}
$$

With an average deviation of $\pm 3.7 \%$ the exponents of (Sc.Gr) in last two equations shows that the natural convection is turbulent ${ }^{29}$ inside the cavity. This turbulence arises as a result of the change in direction of the downward stream when it reaches the cavity bottom.

On comparing the mass transfer coefficient obtained in this work, where a central cathode was placed in the cavity with a previous study, where the cathode was placed outside the cavity ${ }^{16}$. It would be found that using a central cathode placed in the cavity gives rise to a high mass transfer coefficient and higher rates of polishing. This may be attributed to the fact that the catholically generated $\mathrm{H}_{2}$ bubbles induce a radial momentum transfer who enhances the rate of mass transfer at the cavity wall ${ }^{25}$.

Kinetic and thermodynamic of corrosion of cylindrical copper cavities: The values of activation energy were calculated from applying Arrehenius relation (by least squares procedure)

$$
\ln \mathrm{I}=\ln \frac{\mathrm{A}-\mathrm{E}}{\mathrm{RT}}
$$

where $\mathrm{R}$ is the gas constant $\left(8.314 \mathrm{~kJ} \mathrm{~mol}^{-1}\right), \mathrm{E}$ is the activation energy and $\mathrm{A}$ is the frequency factor. Table-1 show that $\mathrm{E}$ increases with increasing phosphoric acid concentration, which may be attributed to steric hindrance of phosphoric acid to activities complex.

TABLE-1

\begin{tabular}{|c|c|c|c|c|c|}
\hline \multirow{3}{*}{$\begin{array}{c}\mathrm{H}_{3} \mathrm{PO}_{4} \\
\text { Conc. } \\
\text { (M) }\end{array}$} & \multicolumn{4}{|c|}{ Anodic limiting current $\left(\mathrm{mA} / \mathrm{cm}^{2}\right)$} & \multirow{3}{*}{$\begin{array}{l}\text { Activation } \\
\text { energy E }(\mathrm{kJ} \\
\left.\text { mol }^{-1}\right)\end{array}$} \\
\hline & \multicolumn{4}{|c|}{$\mathrm{T}(\mathrm{K})$} & \\
\hline & 298 & 303 & 308 & 313 & \\
\hline 6 & 110 & 130 & 155 & 180 & $25.684 \pm 0.422$ \\
\hline 8 & 91 & 110 & 110 & 130 & $18.026 \pm 2.714$ \\
\hline 10 & 70 & 85 & 92 & 110 & $22.294 \pm 2.357$ \\
\hline 12 & 41 & 53 & 70 & 88 & $39.940 \pm 0.828$ \\
\hline 14 & 36 & 44 & 60 & 77 & $28.858 \pm 1.948$ \\
\hline
\end{tabular}

EFFECT OF TEMPERATURE ON THE ANODIC LIMITING CURRENT AT DIFFERENT CONCENTRATION OF $\mathrm{H}_{3} \mathrm{PO}_{4}$

The values for enthalpy of activation $\Delta \mathrm{H}^{*}$, entropy of activation $\Delta \mathrm{S}^{*}$ and free energy of activation $\Delta \mathrm{G}^{*}$ can be obtained by using equations $\mathrm{s}^{30}$ :

$$
\begin{gathered}
\Delta \mathrm{H}^{*}=\mathrm{Ea}-\mathrm{RT} \\
\frac{\Delta \mathrm{S}^{*}}{\mathrm{R}}=\ln \mathrm{A}-\ln \left(\frac{\mathrm{BTe}}{\mathrm{h}}\right) \\
\Delta \mathrm{G}^{*}=\Delta \mathrm{H}^{*}-\mathrm{T} \Delta \mathrm{S}^{*}
\end{gathered}
$$

where B is Boltzmann's constant, $\mathrm{e}=2.7183$, h is Plank's constant, A is Arrhenius constant, T is absolute temperature and $\mathrm{R}$ is the universal gas constant.

$$
\Delta \mathrm{G}^{*}=\mathrm{H}^{*}-\mathrm{T} \Delta \mathrm{S}^{*}
$$

where B is the Boltzman constant, e is 2.7183 and h is Plank's constant.

The free energy $\Delta \mathrm{G}^{*}$, enthalpy $\Delta \mathrm{H}^{*}$ and entropy $\Delta \mathrm{S}^{*}$ of activation were calculate by least squares procedure and the 
values are given in Table-2 together with their standard deviation.

TABLE 2

THERMODYNAMIC PARAMETERS OF ACTIVATION AT $25^{\circ} \mathrm{C}$ AND DIFFERENT $\mathrm{H}_{3} \mathrm{PO}_{4}$ CONCENTRATIONS

\begin{tabular}{cccc}
\hline $\begin{array}{c}\mathrm{H}_{3} \mathrm{PO}_{4} \\
\text { conc. }(\mathrm{M})\end{array}$ & $\begin{array}{c}\Delta \mathrm{H}^{*} \\
\left(\mathrm{~kJ} \mathrm{~mol}^{-1}\right)\end{array}$ & $\begin{array}{c}\Delta \mathrm{G}^{*} \\
\left(\mathrm{~kJ} \mathrm{~mol}^{-1}\right)\end{array}$ & $\begin{array}{c}-\Delta \mathrm{S}^{*} \\
\left(\mathrm{~J} \mathrm{~mol}^{-1} \mathrm{~K}^{-1}\right)\end{array}$ \\
\hline 6 & $23.205 \pm 0.422$ & $61.369 \pm 0.835$ & $128.000 \pm 1.384$ \\
8 & $15.547 \pm 2.714$ & $61.765 \pm 5.363$ & $155.013 \pm 8.885$ \\
10 & $19.815 \pm 2.357$ & $62.458 \pm 4.659$ & $143.026 \pm 7.720$ \\
12 & $37.431 \pm 0.828$ & $63.817 \pm 1.636$ & $88.499 \pm 2.270$ \\
14 & $26.379 \pm 1.948$ & $64.143 \pm 3.836$ & $126.661 \pm 6.330$ \\
\hline
\end{tabular}

Table- 2 represents the variation of these parameters with concentration of phosphoric acid at $25^{\circ} \mathrm{C}$. The profile of the curve obtained predicts that a compensation effect may exist between $\Delta \mathrm{H}^{*}$ and $\Delta \mathrm{S}^{*}$. The high negative values of $\Delta \mathrm{S}^{*}$ indicated a highly ordered species in solution under investigation $^{25}$.

The values of $\mathrm{E}$ depend on the concentration of $\mathrm{H}_{3} \mathrm{PO}_{4}$. $\mathrm{E}$ increases as $\mathrm{H}_{3} \mathrm{PO}_{4}$ concentration increases, the viscosity of solution increases, with decrease of diffusivity of $\mathrm{Cu}^{2+}$ according to Stokes-Einstein equation ${ }^{25}$.

$$
\frac{\mathrm{D} \mu}{\mathrm{T}}=\text { Constant }
$$

where $\mathrm{D}$ is diffusivity of $\mathrm{Cu}^{2+}$ in $\mathrm{cm}^{2} \mathrm{~S}^{-1}, \mu$ is viscosity of solution in Poise and $\mathrm{T}$ is the absolute temperature. Also this increase in solution viscosity with increasing phosphoric acid concentration results in an increase in the diffusion layer thickness which represents the resistance of rate of mass transfer of $\mathrm{Cu}^{2+}$ from anode surface to bulk solution, more activation energy is required.

Isokinetic relationship: Variation in the rate within a reaction series may be caused by changes in either, or both, the enthalpy or the entropy of activation. The correlation of $\Delta \mathrm{H}^{*}$ with $\Delta \mathrm{S}^{*}$ is a linear relationship may be stated algebraically $^{31}$;

$$
\begin{gathered}
\Delta \mathrm{H}^{*}=\beta \Delta \mathrm{S}^{*}+\text { constant } \\
\delta \Delta \mathrm{H}^{*}=\beta \delta \Delta \mathrm{S}^{*}
\end{gathered}
$$

The operator, $\delta$, concerns difference between any two reactions in the series.

Substituting from $\delta \Delta \mathrm{H} *=\beta \delta \Delta \mathrm{S} *$ into the familiar relationship:

$$
\begin{aligned}
& \delta \Delta \mathrm{dH}^{*}=\delta \Delta \mathrm{G}^{*}+\mathrm{T} \delta \Delta \mathrm{S}^{*} \\
& \beta \delta \Delta \mathrm{S}^{*}=\delta \Delta \mathrm{G}^{*}+\mathrm{T} \delta \Delta \mathrm{S}^{*}
\end{aligned}
$$

and when $\quad \delta \Delta \mathrm{G}^{*}=0$ then $\beta \approx \mathrm{T}$

i.e., the slope in a linear plot of $\Delta \mathrm{H}^{*}$ versus $\Delta \mathrm{S}^{*}$ is the temperature at which all the reactions that conform to the line occur at the same rate. $\beta$ is therefore known as the isokinetic temperature.

The value of $\beta$ was found to be $332 \mathrm{~K}$ indicating that, the reaction is enthalpy controlled process ${ }^{31}$.

\section{List of symbols}

I : Limiting current density $\left(\mathrm{A} \mathrm{cm}^{-2}\right)$

$\mathrm{K}$ : Mass transfer coefficient $\left(\mathrm{cm} \mathrm{s}^{-1}\right)$
F : Faraday's constant $=96485 \mathrm{~A} \mathrm{~s} \mathrm{~mol}^{-1}$

D : Cavity diameter

C : Saturation solubility of copper phosphoric acid

D : Diffusivity of $\mathrm{Cu}^{2+}$

IZ : Number of electrons involved in the reaction

ISh : Sherwood number $(\mathrm{Kd} / \mathrm{D})$

Gr : Grashof number $\left[\operatorname{gd}^{3}\left(\rho_{\mathrm{I}}-\rho_{\mathrm{b}}\right) / \mathrm{v}^{2}\right]$

Sc : Schmdit number $(v / D)$

h : Cavity height $(\mathrm{cm})$

$\mathrm{g}:$ : Acceleration gravity $\left(\mathrm{cm} \mathrm{s}^{-2}\right)$

$\rho_{\mathrm{b}}:$ Bulk solution density

$\rho_{\mathrm{I}}:$ Interfacial solution density

$\mu \quad$ : Dynamic viscosity

$v \quad$ : Kinematic viscosity $\left(\mathrm{cm}^{2} \mathrm{~s}^{-1}\right)$

\section{REFERENCES}

1. A.M. Awad, N.A. Abdel Ghany and T.M. Dahy, J. Appl. Surf. Sci., 252, 4320 (2010).

2. S. Abd El-Wanees and E.E. Abd El-Aal, Corros. Sci., 52, 338 (2010).

3. P. Detiner, Electrolytic and Chemical Polishing of Metals, Ondenticn Tel Aviv, Israel (1987).

4. B. Du and F.I. Suni, J. Electrochem. Soc., 151, 375 (2004).

5. P.A. Jaquet, Nature, 135, 1076 (1935).

6. P.A. Jaquet, Trans. Electrochem. Soc., 69, 629 (1936).

7. A.M. Ahmed, Bull. Electrochem., 4, 17 (1988).

8. M.G. Fouad and A.M. Ahmed, Electrochim. Acta, 14, 651 (1969).

9. G.H. Sedahmed and L.W. Shemitt, Chem. Eng. Commun., 23, 1 (1983).

10. S.N. Raicheva, Electrochim. Acta, 28, 8 (1984).

11. B.M. Gamal and A.M. Ahmed, Bull. Electrochem., 4, 951 (1988).

12. A.M. Ahmed, J. Electrochem. Soc. India, 37, 258 (1988).

13. A.E.K. Shaban, 18th European Symposium on Corrosion Inhibitors, p. 2 (1995).

14. D.R. Gabe, Corros. Sci., 12, 113 (1972).

15. M.G. Fouad, F.N. Zein and M.I. Ismail, Electrochim. Acta, 16, 1477 (1971).

16. G.H. Sedahmed and L.W. Shemilt, Surf. Coat. Technol., 27, 279 (1971).

17. G.H. Sedahmed, M.Z. El-Abd, I.A.S. Mansour, A.M. Ahmed and A.A. Wragg, J. Appl. Electrochem., 9, 1 (1979).

18. C.-Y. Huang and S.R. Sheau, Mater. Lett., 30, 357 (1997).

19. A. Sinha and B.P. Sharma, Mater. Res Bull., 37, 407 (2002).

20. A.M. Awad, A.M.E. Abd El-Rahman and M.A. Rafea, J. Am. Sci., 6, 9 (2010).

21. D. Landlt, Electrochim. Acta, 32, 1 (1987).

22. J.R. Scully, H.P. Hack and D.G. Tipton, Corrosion, 42, 462 (1986).

23. W.K. Kelly, R.N. Lyer and H.W. Pickerng, J. Electrochem. Soc., 140, 3134 (1993).

24. S. Magaino, M. Matloz and D. Landolt, J. Electrochem. Soc., 140, 1365 (1993).

25. A.A. Taha, S.A. Sallam and A.M. Ahmed, Anticorros. Methods Mater., 41, 10 (1994).

26. A.M. Ahmed and G.H. Sedahmed, J. Mater. Sci. Lett., 9, 270 (1990).

27. C.H. Huang, F.-Y. Hsu and S.H. Yu, Corros. Sci., 53, 589 (2011).

28. W.J. McGTergart and M.Z. El-Abd, The Electrolytic and Chemical Polishing of Metals in Research and Industry, Pergamon Press, London, p. 168 (1959).

29. W.D. Dekwer, Chem. Eng. Sci., 37, 1341 (1980).

30. S. Glasston, K.J. Laidler and H. Eyring, The Theory of Rate Processes, McGraw-Hill, New York, p. 477 (1941).

31. J.E. Leffler and E. Grun Wald, Rates and Equlibria of Organic Reactions, John Wiley, New York, p. 285 (1963). 